\title{
Lecciones de EI Lado Tenebroso: las moralejas de la historia de la guerra de EE.UU. contra el terrorismo
}

Este comentario, junto a los documentos que analiza, está disponible en www.anuariocdh.uchile.cl

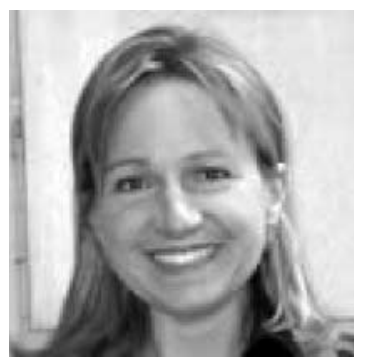

\begin{abstract}
Christine Cervenak
Directora de Desarrollo Institucional del Centro de Derechos Humanos $(\mathrm{CDH})$ de la Facultad de Derecho, Universidad de Chile (Santiago, Chile).

Abogada estadounidense, especializada en Derecho Internacional y Resolución de Conflictos. Trabajó en la Oficina del Asesor Legal del Departamento de Estado de EE.UU., y para las Naciones Unidas en Cisjordania y El Salvador. Ha realizado trabajos como consultora para la Universidad de Harvard, The Asia Foundation, el Gobierno de Bolivia, y la Fundación Poder Ciudadano (Argentina), entre otras instituciones. Antes de ingresar al $\mathrm{CDH}$, se desempeñó como Coordinadora de Pro Acceso en Chile. Posee un Juris Doctor de UCLA y un Bachillerato en Gobierno y Relaciones Internacionales de la Universidad de Notre Dame. Además, fue Visiting Fellow del Harvard Law School, en el Programa de Derechos Humanos.

ccervenak@derecho.uchile.cl.
\end{abstract}

\section{RESUMEN}

El gobierno del Presidente Bush justificó las múltiples violaciones a la Constitución de EE.UU., los principios fundamentales de gobierno del país, y las disposiciones de los tratados internacionales, aduciendo que tales transgresiones eran necesarias debido a la guerra contra el terrorismo. En el libro The Dark Side: The Inside Story of How the War on Terror Turned into a War on American Ideals [EI Lado Tenebroso: los Entretelones de la Transformación de la Guerra contra el Terrorismo en una Guerra contra los Ideales Estadounidenses], su autora, Jane Mayer, demuestra claramente cómo la combinación nefasta del débil liderazgo del Presidente George W. Bush, junto con el celo e inclinación por el secreto del Vicepresidente Richard Cheney, erosionaron el tejido legal y las políticas de Estados Unidos que protegen los derechos fundamentales. El presente artículo se basa en el trabajo de Mayer para explicar cómo los funcionarios estadounidenses crearon un torcido marco legal y de políticas públicas, la forma en que se descubrieron los actos frecuentemente ilegales en que incurrieron y las lecciones que de ello pueden extraerse para América Latina.

\section{Introducción}

En el artículo siguiente, "La guerra contra el terrorismo y el estado de derecho", Owen Fiss, profesor de la Escuela de Derecho de la Universidad de Yale, plantea que la declaración de la "guerra contra el terrorismo" fue el inicio de una "etapa única en el derecho estadounidense que comenzó el 11 de septiembre del 2001 y continúa hasta el día de hoy" (Fiss, p. 215). Las verdaderas guerras emprendidas por Estados Unidos en nombre de la guerra contra el terrorismo -en Afganistán, Irak y contra Al Qaeda- generan enormes tensiones para ese país. Como señala el Profesor Fiss, si bien las exigencias de la guerra pueden requerir de cambios en las leyes y reglamentos "el supuesto predominante de la sociedad estadounidense es que estas medidas[...] se adoptarán dentro de los términos señalados en la Constitución: que se observará la asignación de poderes entre las distintas ramas establecidas en la Constitución y que se respetarán las libertades fun- 
damentales. Nuestra Constitución rige tanto en tiempo de guerra, como en tiempos de paz" (Fiss, p. 217). El Profesor Fiss luego detalla las violaciones cometidas por el gobierno del Presidente Bush en contra de la Constitución de EE.UU., los principios fundamentales del gobierno de EE.UU. y las disposiciones de los tratados internacionales, todas las cuales se han justificado aduciendo la guerra contra el terrorismo.

Dichas transgresiones generaron un caleidoscopio horroroso de violaciones específicas de los derechos humanos: detalles de la tortura aplicada a cientos de personas detenidas por EE.UU.; fotografías de los prisioneros de Abu Ghraib donde se ven los horribles abusos que padecieron; la entrega de prisioneros detenidos por EE.UU. a centros de tortura en Siria, Egipto y otros lugares; las prisiones secretas de la CIA, Ilamadas "sitios negros"; el campo de detención de la Bahía de Guantánamo, que fue calificado por Amnistía Internacional como "el Gulag de nuestra época"; y el espionaje sin precedentes en contra de ciudadanos estadounidenses realizado por su propio gobierno, en violación de los derechos civiles. Esta situación hace añicos la reputación de Estados Unidos en el área de los derechos humanos, como demuestra el que Canadá haya incluido a su vecino del Sur en la lista de Estados "descarriados" que recurren a la tortura. Para Estados Unidos, esto es una ruptura extrema con su anterior y tradicional papel de paladín autodesignado de los derechos fundamentales. Este papel se originó en la Guerra de Independencia, cuando el General George Washington juró que los enemigos capturados serían tratados en forma humanitaria (a diferencia de la costumbre británica de torturar a sus prisioneros), pasando por el liderazgo desempeñado por EE.UU. en la redacción de numerosos tratados de derechos humanos, incluida la Convención contra la Tortura de 1984. Los ideales estadounidenses aportaron la base para el derecho internacional humanitario; Estados Unidos es el custodio de los ejemplares originales de los Convenios de Ginebra de 1949, los cuales se guardan en una bóveda del Departamento de Estado de EE.UU.

Las pruebas muestran que las atrocidades descritas anteriormente no fueron cometidas por agentes descarriados o simplemente por "unas pocas manzanas podridas". Más bien, fueron el resultado de políticas intencionales, dictadas desde el más alto nivel del Poder Ejecutivo de EE.UU. cuyo fin era hacer caso omiso de normas fundamentales vigentes en EE.UU. y del derecho internacional. El libro de Jane Mayer -publicado en 2008- The Dark Side: The Inside Story of How the War on Terror Turned into a War on American Ideals ${ }^{1}$, describe de manera apasionante y minuciosa cómo funcionarios de alto nivel al interior del gobierno de EE.UU. diseñaron e implementaron estas políticas -a menudo a puertas cerradas- y el enorme costo que ello ha acarreado en términos del sufrimiento individual de las víctimas, el debilitamiento de la posición moral de EE.UU. y el socavamiento de la lucha en contra de Al Qaeda.

\section{Todos los hombres del Vicepresidente}

Mayer revela diestramente cómo la combinación nefasta del débil liderazgo del Presidente George W. Bush, junto con el celo e inclinación por el secreto del Vicepresidente Richard Cheney, erosionaron el tejido legal y las políticas de Estados Unidos destinadas a proteger los derechos fundamentales. El Presidente Bush aparece como un personaje secundario en esta historia, una persona con serios defectos de carácter: su ignorancia sobre temas importantes y su falta de curiosidad, se combinan peligrosamente con su tendencia a tomar decisiones rápidas e irreflexivas. El Vicepresidente Cheney, por otra parte, era el titiritero maestro; una persona familiarizada con los círculos de poder desde larga data; un político motivado por su propia agenda, cuyo fin era

1 MAYER, J. The Dark Side: The Inside Story of How the War on Terror Turned into a War on American Ideals. Nueva York. Doubleday Publishing Group, 2008 (en adelante "Mayer"). 
fortalecer la Presidencia de EE.UU. mediante la eliminación de las actuales restricciones que la limitan; un experto en el trabajo detrás de las bambalinas, quien sabe manipular a sus partidarios y a quienes temen oponérsele. Cheney, quien fue Jefe de Gabinete de la Casa Blanca en el período del Presidente Gerald Ford y luego congresista, ha sido descrito como "un fanático redomado" del Poder Ejecutivo, que no cree en el equilibrio de las tres ramas del gobierno². Al igual que muchos miembros del Partido Republicano, le preocupaba el vicio de "demasiada legislación internacional, demasiados derechos civiles, demasiadas limitaciones al poder del Presidente para conducir una guerra, demasiados derechos para los inculpados, demasiadas reglas contra acciones encubiertas de carácter letal. También consideraba que existía una transparencia gubernamental excesiva y una desmedida intromisión de parte del Congreso y la prensa" ${ }^{3}$. Colin Powell, ex Secretario de Estado, señaló confidencialmente que el "[Presidente Bush] tiene estas características de vaquero tejano y cuando uno sabe cómo llegarle, puede lograr que haga cosas realmente tontas. Hay que utilizar esos aspectos fanfarrones de su autoimagen. Cheney sabía exactamente cómo lograrlo" ${ }^{\prime 4}$.

Cheney tenía un poderoso adlátere: David Addington, su principal asesor legal y más adelante su Jefe de Gabinete, quien fue su estrecho colaborador para garantizar el secreto de sus acciones y para aislar al Presidente, junto con aplicar un barniz de legitimidad legal a sus fechorías. Con un currículum impresionante, en su calidad de graduado de la Escuela de Servicio Exterior de la Universidad de Georgetown y la Facultad de Derecho de la Universidad de Duke, Addington había trabajado muchos años como abogado del gobierno y era experto en el tema de la sucesión presidencial. Su personalidad -vengativo, seguro de sí mismo, carente de respeto por quienes no comparten sus opiniones, además de su mal genio- lo convertían en un colega muy poco dado a la consulta y la colaboración. Se impuso como alguien indispensable en la guerra contra el terrorismo, denigrando a quienes manifestaban preocupación por temas relacionados con el derecho internacional como personas "blandas frente al terrorismo" ${ }^{5}$.

Cheney, Addington y un pequeño grupo de otros republicanos con cargos de designación política, se esforzaban por promover una tendencia al interior del Partido Republicano que buscaba establecer un "poder ejecutivo unitario" bajo un "nuevo paradigma" basado en el concepto de que el Poder Ejecutivo estadounidense tiene un poder inherente para llevar a cabo la defensa nacional, que no está limitado por la Constitución Política. Esta doctrina, que suele describirse como "presidencia imperial", sostiene que "el Presidente, en su calidad de Comandante en Jefe, tiene la autoridad necesaria para no tomar en cuenta los límites legales existentes si así lo requiere la seguridad nacional" 6 . Esta interpretación extrema, compartida por escasos juristas, se podría describir, siendo generosos, como una "nueva forma" de interpretar la Constitución. La mayoría de los abogados, incluidos muchos abogados conservadores de alto nivel, estiman que es mucho más peligrosa. El ex Secretario de Estado, Colin Powell, hizo un comentario muy esclarecedor al respecto: "[Addington] no cree en la Constitución"7.

Cheney y Addington se dieron cuenta de que el 11 de septiembre del 2001 y la guerra contra el terrorismo, les ofrecía una oportunidad sin precedentes para poner en práctica esta agenda en nombre de la seguridad nacional. Cheney resumió su modus operandi en el programa televisivo

\footnotetext{
2 Ver los comentarios de Evan Thomas, de la revista Newsweek, en la sección FRONTLINE: Transcripción, Cheney's Law: http://www.pbs.org/wgbh/pages/frontline/cheney/etc/script.html [consultado el 15 de diciembre de 2008].

3 MAYER, p. 7.

4 MAYER, p. 125

5 MAYER, p. 64.

6 MAYER, p. 51.

7 MAYER, p. 87.
} 
Meet the Press [Reunión con la prensa], transmitido el domingo después del 11 de septiembre de 2001:

Tendremos que trabajar en el lado tenebroso, por así decirlo... Gran parte de lo que hay que hacer tendrá que hacerse discretamente, sin discusión, recurriendo a las fuentes y los métodos que emplean nuestras agencias de inteligencia... Y...este... de modo que será indispensable utilizar básicamente cualquier medio a nuestra disposición para lograr nuestros objetivos ${ }^{8}$.

Varios años después, un ex alto funcionario de gobierno explicó que Cheney creía que "la seguridad de Estados Unidos era una cuestión suprema en relación con todo lo demás y que se podía lograr la seguridad perfecta. No lo puedo culpar por procurar la seguridad de EE.UU., pero estaba dispuesto a corromper a todo el país para resguardarla" ${ }^{\prime 9}$.

Como veterano de la burocracia del Poder Ejecutivo, y a pesar de no ser abogado, Cheney entendía la importancia de generar "escudos dorados" para legitimar cualquier ampliación del poder ejecutivo fuera de los límites aceptados. Los "escudos dorados" son opiniones legales emitidas por el asesor legal de la Casa Blanca, la Oficina del Asesor Legal del Departamento de Justicia, cuyo objeto es justificar decisiones tomadas por el Poder Ejecutivo con el fin de proteger a los funcionarios estadounidenses que actúan de buena fe frente al riesgo de posibles acciones legales por las actividades relacionadas con dicha opinión. Como señala Mayer:

Casi inmediatamente después del 11 de septiembre del 2001, Cheney tomó las medidas necesarias para que algunos de los abogados más agudos y mejor capacitados del país se dedicaran a trabajar en secreto en la Casa Blanca y en el Departamento de Justicia de EE.UU. con el fin de producir justificaciones legales relacionadas con una extraordinaria expansión del poder del ejecutivo para llevar a cabo la guerra contra el terrorismo ${ }^{10}$.

Este "Consejo de Guerra" -así denominado por los abogados integrantes- consistía de personas que realmente creían en la presidencia imperial, e incluía a un actor clave de la Oficina del Asesor Legal del Departamento de Justicia: John Yoo, egresado de Harvard y de la Facultad de Derecho de la Universidad de Yale, profesor de Derecho de la Universidad de California en Berkeley, reconocido por su carácter extremadamente conservador y partidario activo del ejecutivo unitario. El Consejo de Guerra se dedicó a elaborar una serie de memorandos legales abogando por el concepto de la superioridad del Poder Ejecutivo respecto de las demás ramas del gobierno de EE.UU. Supuestamente, estas opiniones constituían la base legal para las órdenes presidenciales consideradas atentatorias contra el meollo del derecho constitucional estadounidense y el derecho internacional, pues otorgaban al Presidente los poderes necesarios para detener, interrogar, torturar e interceptar conversaciones sin autorización del Congreso ni supervisión judicial. Los memorandos del Consejo de Guerra eran redactados en secreto por un grupo de gente que realmente creía en esta idea y que estaban comprometidos con la idea del poder ejecutivo unitario sin respeto alguno por el sistema de controles y equilibrios establecido en la Constitución de EE.UU., personas ignorantes, sin ningún aprecio por el derecho internacional y carentes de todo interés por tomar en cuenta la prudencia, ética y moralidad de sus conclusiones. Operaban a puerta cerrada y los ejemplares únicos de sus memorandos se guardaban bajo siete llaves. Una vez redactados, estos memorandos legales eran presentados -junto con el borrador del Decreto Supremo- al Presidente Bush para su firma, sin la asesoría ni el conocimiento de "afuerinos" tales

MAYER, pp. 9-10.

9 MAYER, p. 7, citando a Lawrence Wilkerson, ex Jefe de Gabinete del Secretario de Estado Colin Powell.

10 MAYER, pp. 7-8. 
como el Asesor de Seguridad Nacional, el Secretario de Estado y, mucho menos, los asesores legales de alto nivel.

Las operaciones del Consejo de Guerra eludían intencionalmente los mecanismos y procedimientos normales del gobierno de EE.UU. para hacer frente a situaciones complejas, tales como los procesos establecidos de consultas entre agencias de gobierno en que participan expertos legales y que requieren la aprobación de todos los organismos y departamentos del Poder Ejecutivo que se vean afectados por las decisiones. A fines de 2001, en un despliegue de cinismo particularmente censurable, el Jefe de Gabinete de la Casa Blanca, Alberto Gonzales, le encargó a un comité formado por representantes de diversas agencias interestatales que preparara propuestas para el trato de los capturados en la guerra contra el terrorismo. Paralelamente, en forma secreta, el Consejo de Guerra, incluido el mismo Gonzales, desarrolló un memorando amparado en el "escudo dorado" justificando el Decreto Supremo firmado por Bush en noviembre del 2001 que establecía comisiones militares para el juzgamiento de prisioneros (lo cual, en opinión de los expertos, es una aplicación errónea del Artículo Común № 3 de las Convenciones de Ginebra, el cual señala en su número 1.d que se prohíben "las condenas dictadas y las ejecuciones sin previo juicio ante un tribunal legítimamente constituido, con garantías judiciales reconocidas como indispensables por los pueblos civilizados"). Respecto de esta labor desarrollada en forma paralela, se cita a Addington, quien señaló: "[q]ue se joda el proceso inter-agencias"11. La primera noticia que Colin Powell, Secretario de Estado, tuvo del Decreto Supremo fue mientras miraba un programa de $\mathrm{CNN}$, sumado al hecho de que ningún otro funcionario de alto nivel había tenido acceso a la opinión del Consejo de Guerra ni al borrador del Decreto Supremo antes de que entrara en vigencia. Posteriormente, se descubrió que el análisis legal se basaba en un caso obsoleto de la Corte Suprema y transgredía lo dispuesto en el Código Uniforme de Justicia Militar de EE.UU.

Una persona cercana al círculo de poder de Cheney describió los memorandos del Consejo de Guerra -sobre los cuales posteriormente se reconoció que fueron redactados por abogados que no sabían de historia militar, desconocían los Juicios de Nuremberg, las leyes de la guerra y las Convenciones de Ginebra- como "endebles opiniones legales que se mantuvieron en estricta reserva para que nadie cuestionara la base legal de las operaciones" y un "revoltijo legal"12. Un memorando secreto del Consejo de Guerra particularmente perturbador, es una opinión del año 2002 que señala que, a pesar de que las Convenciones de Ginebra no se aplican a los combatientes ilegales, Estados Unidos trataría a los detenidos en forma humanitaria conforme a "las necesidades militares"-la misma justificación legal que usaron los japoneses como excusa para la "Marcha de la Muerte de Batán"13.

El Consejo de Guerra -y Addington en particular- utilizó un mecanismo establecido conocido como "declaraciones presidenciales al momento de firmar" con el fin de socavar la legislación aprobada por el Congreso. El objeto de estas declaraciones -que se emiten al momento en que el Presidente rubrica la ley- es informar sobre la forma en que el Presidente implementará la ley. El Consejo de Guerra las redactaba en secreto con el fin de debilitar los esfuerzos del Congreso por controlar los excesos del Poder Ejecutivo. La utilización de este mecanismo por parte del Presidente Bush fue sin precedentes: el periódico The Boston Globe ha identificado cientos de estas "declaraciones presidenciales al momento de firmar" pero posiblemente existen miles. El secreto excesivo que rodeaba las opiniones legales y las declaraciones presidenciales -supuesta-

\footnotetext{
11 MAYER, p. 80.

12 MAYER, p. 70, cita de Jack Goldsmith, ex Director de la Oficina de Asesoría Legal y autor del libro THE TERROR PRESIDENCY, publicado en junio del 2007.

13 MAYER, pp. 124-25.
} 
mente para evitar filtraciones- "permitieron que la oficina del Vicepresidente pusiera en práctica políticas muy cuestionables, que habrían tenido pocas probabilidades de sostenerse en un debate público"14.

\section{La lucha contra el lado tenebroso}

A pesar de que no se ha podido calcular plenamente el costo de las políticas aplicadas por el gobierno del Presidente Bush en la guerra contra el terrorismo, desde un principio fue evidente que ocasionaban daños graves: dichas políticas favorecieron el aumento de yihadis; sabotearon el enjuiciamiento de los acusados de terrorismo; provocaron la renuncia de agentes experimentados del FBI, asqueados con las técnicas de tortura; generaron información falsa y engañosa obtenida bajo tortura (entre la cual se incluyen los motivos erróneos en que se basó la invasión estadounidense de Iraq en el año 2003) y debilitaron los valores fundamentales de EE.UU. en términos éticos y legales, lo cual tuvo un efecto catastrófico en la influencia y el papel desempeñado por EE.UU. en el exterior.

Si bien las personas individualizadas anteriormente se dedicaron a socavar el estado de derecho, las fuerzas democráticas existentes han ayudado a limitar el daño, o incluso a empezar a revertirlo. La separación de poderes que establece la Constitución de EE.UU., que se basa en un sistema de controles y equilibrios, permitió que el Congreso y los tribunales federales hicieran valer su papel en cuanto a controlar e incluso revertir los abusos cometidos. Como señala el Profesor Fiss en su artículo, los tribunales federales e incluso la Corte Suprema han ratificado principios legales fundamentales. Una decisión clave fue el fallo histórico de junio del 2008 en el caso Boumediene con Bush (2008), que ratifica el derecho de hábeas corpus de los detenidos en la Bahía de Guantánamo. En virtud de esta sentencia dictada por un tribunal federal, se exigió la liberación de un grupo conformado por 17 musulmanes de origen chino de la etnia Uigur, detenidos sin formulación de cargos desde el 2002. Mediante la Ley de Trato de los Detenidos del año 2005, patrocinada por John McCain, Senador Republicano y ex prisionero de guerra, el Congreso de EE.UU. ratificó la prohibición contra la tortura establecida en la Constitución de los EE.UU. Al tiempo que algunos miembros del Congreso se esforzaban en investigar las acciones ilegales del Poder Ejecutivo antes del año 2006, la elección que le entregó a los demócratas el control de ambas cámaras ese año produjo un cambio radical en la solidez de la fiscalización de parte del Congreso. Las investigaciones realizadas por el Congreso, las audiencias públicas y la publicación de documentos desclasificados cuestionaron la sensación de invulnerabilidad del gobierno del Presidente Bush. Dos ejemplos de lo anterior, entre muchos otros, son los siguientes: algunos senadores estadounidenses enfrentaron a la Casa Blanca para que ésta hiciera públicos documentos secretos; también se obtuvo la renuncia de uno de los integrantes del Consejo de Guerra, el Ministro de Justicia (Attorney General) Alberto Gonzales, luego de su lamentable desempeño en las audiencias del Congreso.

Al mismo tiempo, una serie de actores de la sociedad civil desempeñaron un papel fundamental para revelar y limitar los abusos. Aunque hay múltiples ejemplos particulares, los más sobresalientes incluyen los siguientes: el Informe de los Médicos por los Derechos Humanos [Physicians for Human Rights] del año 2008, que describe en detalle las torturas cometidas por personal estadounidense contra personas específicas; abogados imparciales de todo el país dedicados a defender a los detenidos, como Tom Wilner, de la prestigiosa firma de abogados Shearman \& Sterling, quien representó a 12 detenidos kuwaitíes; la Asociación Estadounidense para las Libertades Ciudadanas [American Civil Liberties Union] que, en virtud de la Ley de Libertad de Información de EE.UU.,

14 MAYER, pp. 268-69, resumen de las conclusiones de Jack Goldsmith. 
luchó para obtener documentos acerca de las técnicas de tortura utilizadas en los centros de detención manejados por Estados Unidos; además de la crítica a las políticas de EE.UU. por la violación del derecho internacional de renombrados profesores de derecho.

Si bien se ha acusado a la gran mayoría de los medios de comunicación estadounidense de no cumplir con sus obligaciones como "cuarto poder" en lo referente a proporcionar la información necesaria para el debate público y criticar los abusos de poder, también hay ejemplos muy destacables de ciertos medios de comunicación que investigaron a fondo instancias de atrocidades cometidas por agentes de EE.UU., que demostraban que la responsabilidad recaía en muchos casos en los más altos niveles del gobierno. El mejor periodismo de investigación de EE.UU. ha evidenciado su poder y ha producido revelaciones impresionantes que han tenido gran impacto en la sociedad estadounidense y otras partes del mundo, en cuanto a temas tales como las prisiones secretas y los Ilamados "sitios negros", las torturas aplicadas en instalaciones controladas por EE.UU., las iniciativas ilegales de vigilancia y el abuso de poder durante el gobierno del Presidente Bush (entre los más importantes de los cuales se encuentra The Dark Side). Esto es producto del trabajo arduo y comprometido por periodistas, "blogueros" y los principales medios de comunicación (como los periódicos The Washington Post, The New York Times, Los Angeles Times, The Boston Globe y la revista Newsweek). Algunos de los casos más notables en que los medios de comunicación informaron al público estadounidense de los abusos cometidos por el gobierno del Presidente Bush provienen de la serie Frontline, programa del Servicio de Radiodifusión Pública apoyado por el gobierno federal, tales como sus documentales "La Ley de Cheney" ("Cheney's Law") y "Torturando a la Democracia" (Torturing Democracy).

De especial valor inspirador entre las personas que "le dicen la verdad a los poderosos" están las descripciones de Mayer sobre funcionarios de gobierno -que suelen ser personas nombradas por motivos políticos dada su pertenencia al Partido Republicano-, que arriesgaron sus carreras y reputación para proteger las leyes y los valores de EE.UU. Muchos de ellos, de gran integridad profesional, simplemente fueron avasallados. Un ejemplo notable es el de una joven abogada del Departamento de Justicia, Jesselyn Radick, quien defendió el derecho de John Lindh -ciudadano estadounidense detenido- a que se le tratara conforme a la ley, hecho que le costó su trabajo y le significó verse sometida a una investigación penal, además de ser objeto de registros en que debía desvestirse cada vez que deseaba abordar un avión, todo ello motivado aparentemente por el hecho de rebelarse contra la "línea del Partido". William Howard Taft IV, Asesor Legal del Departamento de Estado, enfrentó a John Yoo al presentar un memorando legal de 40 páginas el 11 de enero de 2002. En el documento señalaba que el análisis de Yoo adolecía de "graves defectos" y, además, afirmaba que el Presidente Bush podría ser enjuiciado por crímenes de guerra ${ }^{15}$. John Bellinger, el abogado de más alto nivel de la Seguridad Nacional, dejó en claro en el año 2002 que, en su opinión, detener e interrogar a personas inocentes mediante el uso de técnicas tan inhumanas constituía un crimen de guerra. Alberto Mora, Asesor Jurídico General de la Armada de EE.UU., se arriesgó a una acusación de insubordinación por criticar las torturas aplicadas en Guantánamo y luchó con fuerza desde el gobierno por frenar precisamente aquellos abusos que posteriormente se conocieron sobre Abu Ghraib. Como resultado de los esfuerzos de Mora, el Secretario de Defensa Donald Rumsfeld, suspendió la aprobación de las cuestionadas técnicas de interrogación en el 2003. Hubo agentes experimentados del FBI, interrogadores profesionales, quienes, horrorizados ante la autorización oficial de la tortura, cuestionaron estas políticas y, finalmente, terminaron por renunciar indignados.

15 MAYER, p. 122. 
El más eficaz de estos disidentes internos quizás haya sido el abogado Jack Goldsmith, amigo de John Yoo, quien llegó a ser el Jefe de la Oficina de Asesoría Legal en octubre del 2003. A las seis semanas de asumir el cargo, Goldsmith exigió leer los memorandos secretos o "escudos dorados". Cuanto más leía, más aumentaba su preocupación ante los vergonzosos razonamientos legales utilizados para fundamentar importantes decisiones, tales como los relacionados con los interrogatorios "intensificados" y los programas de espionaje nacional. Goldsmith logró resistir el acoso de Addington, quien lo presionaba para que ratificara los memorandos y, en última instancia, Goldsmith rescindió algunos de estos "escudos dorados" en junio del año 2004 y luego renunció a su cargo ${ }^{16}$.

\section{Una moraleja para América Latina}

En última instancia, el poder del voto logró producir un "cambio de guardia" con el triunfo electoral del Presidente Barack Obama, quien se opuso a la invasión de Iraq y que, durante su campaña, prometió clausurar el centro de detención de la Bahía de Guantánamo, además de hacer un Ilamado a poner fin a las técnicas "intensificadas" que se utilizaban en los interrogatorios. El Presidente Obama enfrenta el desafío de encontrar un equilibrio para su propio gobierno entre restablecer los valores del estado de derecho y proteger la seguridad nacional, pero ha sido muy claro en señalar que le asignará la mayor prioridad a la transparencia.

Como demuestra la situación existente en Estados Unidos desde el 11 de septiembre del 2001, "[e]l temor y la angustia de un país han sido aprovechados por gente fanática y tonta"17. Esta peligrosa combinación no es novedad alguna para los países latinoamericanos que ya han vivido en carne propia la desgracia de la tortura, las desapariciones, los abusos de poder, la censura, la corrupción y el culto al secreto en forma generalizada, todo en nombre de la seguridad nacional.

De esta experiencia tan reciente de EE.UU. de cometer abusos legales en nombre de la guerra contra el terrorismo, es posible identificar el papel de ciertas líneas de defensa para contrarrestarlos, como se señaló anteriormente. Estos "anticuerpos" democráticos operan como fuerzas compensatorias frente al secreto y la falta de transparencia, reivindicando los derechos propiamente democráticos de la rendición de cuentas (accountability) y la participación política. En Estados Unidos están en juego una serie de estas fuerzas y es imprescindible que las democracias latinoamericanas respalden el desarrollo constante de estas mismas fuerzas en el ámbito local, mediante el fortalecimiento de los medios de comunicación masiva y el periodismo de investigación; el buen ejercicio de la profesión por parte de abogados guiados por principios; funcionarios de gobierno orientados por valores democráticos (y éticos) fundamentales; una sociedad civil activa que exija rendición de cuentas y el acceso a la información; una estructura sana de controles y equilibrios entre las funciones del Poder Legislativo, el Poder Ejecutivo y el Poder Judicial y, evidentemente, elecciones libres, periódicas y justas, para así eliminar, por medio del voto, a los "fanáticos y los tontos".

\footnotetext{
16 Ver MAYER, pp. 261-294.

17 MAYER, p. 335, cita tomada de Philip Zelikow, quien fuera Director Ejecutivo de la Comisión del 11 de Septiembre y posteriormente asistente de la Secretaria de Estado, Condoleezza Rice.
} 